\begin{tabular}{|c|c|}
\hline Title & Highly Enhanced Corrosion Resistance of Stainless Steel by Sol-Gel Layer-by-Layer A luminosilicate Thin Coatings \\
\hline Author(s) & Habazaki, Hiroki; Kimura, Taiki; A oki, Y oshitaka; Tsuji, Etsushi; Y ano, Takayoshi \\
\hline Citation & $\begin{array}{l}\text { Journal of the electrochemical society, 161(1), C57-C61 } \\
\text { https://doi.org/10.1149/2.060401jes }\end{array}$ \\
\hline Issue Date & 2014 \\
\hline Doc URL & http:/hdl .handle.net/2115/55140 \\
\hline Rights & $\begin{array}{l}\text { () The Electrochemical Society, Inc. 2014. All rights reserved. Except as provided under U.S. copyright law, this work } \\
\text { may not be reproduced, resold, distributed, or modified without the express permission of The Electrochemical Society } \\
\text { (ECS). The archival version of this work was published in Journal of the electrochemical society. }\end{array}$ \\
\hline Type & article \\
\hline File Information & C57.full.pdf \\
\hline
\end{tabular}

Instructions for use 


\title{
Highly Enhanced Corrosion Resistance of Stainless Steel by Sol-Gel Layer-by-Layer Aluminosilicate Thin Coatings
}

\author{
Hiroki Habazaki, ${ }^{a, b, *, z}$ Taiki Kimura, ${ }^{\text {b }}$ Yoshitaka Aoki, ${ }^{a, b}$ Etsushi Tsuji, ${ }^{a}, b$ \\ and Takayoshi Yano ${ }^{\mathrm{c}}$
}

\author{
${ }^{a}$ Division of Materials Chemistry \& Frontier Chemistry Center, Faculty of Engineering, Hokkaido University, Sapporo, \\ Hokkaido 060-8628, Japan \\ ${ }^{b}$ Graduate School of Chemical Sciences and Engineering, Hokkaido University, Sapporo, Hokkaido 060-8628, Japan \\ ${ }^{c}$ Steel Research Laboratory, JFE Steel Corporation, Chiba 260-0835, Japan
}

\begin{abstract}
In this study, aluminosilicate sol-gel coatings were deposited on Type 430 stainless steel by multiple spin casting cycles. Amorphous aluminosilicate coatings, $65 \mathrm{~nm}$ thick, were prepared from precursor solutions with 50,100 , and $500 \mathrm{mmol} \mathrm{dm}^{-3}$ total concentrations of aluminum and silicon species (molar ratio of $\mathrm{Al} / \mathrm{Si}=1 / 4$ ) by 10,5 , and 1 spin casting cycles, respectively. Although the obtained coatings had a similar composition with a molar ratio of $\mathrm{Al} / \mathrm{Si}=25 / 75$, the coatings with increased density were formed by reducing the concentration of precursor solution. The pitting potentials of the coated stainless steels, measured by potentiodynamic polarization in $3.5 \% \mathrm{NaCl}$ solution, increased remarkably (to $1.1 \mathrm{~V}$ vs $\mathrm{Ag} / \mathrm{AgCl}$ ) with a decrease in the concentration of precursor solution. Cyclic corrosion tests, consisting of 30 cycles of spraying of $5 \% \mathrm{NaCl}$ solution at $35^{\circ} \mathrm{C}$ for $2 \mathrm{~h}$, drying at $60^{\circ} \mathrm{C}$ for $4 \mathrm{~h}$, and wetting at $50^{\circ} \mathrm{C}$ and $>95 \%$ relative humidity for $2 \mathrm{~h}$, revealed highly improved corrosion resistance. Layer-by-layer sol-gel deposition using diluted precursor solutions is an effective way to obtain highly protective coatings.

(C) 2013 The Electrochemical Society. [DOI: 10.1149/2.060401jes] All rights reserved.
\end{abstract}

Manuscript submitted October 14, 2013; revised manuscript received November 12, 2013. Published November 22, 2013.

Metallic materials have been widely used in structural, marine, automobile, and aircraft applications. They are highly susceptible to corrosion in aggressive environments, and corrosion is one of the main contributors to materials loss in our society. Protective coatings have often been applied for corrosion protection. It has been well accepted that chromate coatings are the most effective, and have been applied as a suitable surface treatment of aluminum, magnesium, and steels. However, recent tighter regulations restrict the use of chromates due to their toxicity. As a consequence, the development of novel coatings with low environmental impact has attracted attention in the last decade.

Sol-gel processing is one of the prospective candidates for the production of corrosion protection coatings with low environment impact. Sol-gel films usually have good adhesion to both metallic substrates and organic top coatings. The low temperature processing of the solgel method, compared with usual ceramic coatings, is important for the substrates that show mechanical degradation when exposed to environments at elevated temperatures. Thus, sol-gel processing has been extensively studied for corrosion protection of metals, including aluminum, magnesium, and steels. ${ }^{1}$ Sol-gel coatings based on $\mathrm{SiO}_{2},{ }^{2-6} \mathrm{ZrO}_{2},{ }^{7-9}$ and $\mathrm{Al}_{2} \mathrm{O}_{3}{ }^{10,11}$ have been reported to provide good corrosion protection on various metals. However, there are still some drawbacks of inorganic sol-gel coatings: (i) it is difficult to form thick coatings $(>1 \mu \mathrm{m})$ without cracking; ${ }^{12}$ (ii) porosity usually exists in the coatings because the removal of organic components during heattreatment (usually at $400-600^{\circ} \mathrm{C}$ ) introduces micropores in the coatings, through which corrosive solutions can penetrate to substrate. ${ }^{13}$ In order to overcome these drawbacks, increased interest has been directed toward organic-inorganic hybrid sol-gel systems with enhanced barriers against corrosion. The corrosion-protective hybrid coatings were pioneered by van Ooij et al., ${ }^{14,15}$ and many examples have been reported to show the improved corrosion resistance of metals with the hybrid sol-gel coatings. ${ }^{6,16-35}$ However, the coatings with organic components cannot be used at elevated temperatures $\left(>200^{\circ} \mathrm{C}\right)$.

Recently, high density and defect-free thin oxide films free from organic species have been fabricated by a layer-by-layer sol-gel processing and the obtained thin films revealed interesting properties as dielectric ${ }^{36,37}$ and proton-conducting materials. ${ }^{38,39}$ In the layer-bylayer sol-gel processing, the thickness of the film developed by one processing cycle was less than $10 \mathrm{~nm}$. Thus, layer-by-layer deposition of nm-thick oxide films is also of interest as a protective layer for corrosion protection. The thin aluminosilicate film of 40-300 nm thickness

\footnotetext{
*Electrochemical Society Active Member.
}

${ }^{\mathrm{z} E-m a i l: ~ h a b a z a k i @ e n g . h o k u d a i . a c . j p ~}$ fabricated by a layer-by-layer deposition process revealed efficient proton conductivity at elevated temperatures of $\sim 400^{\circ} \mathrm{C}$. When this aluminosilicate film was used as a solid electrolyte for a hydrogen concentration cell, an electromotive force close to the theoretical value was obtained. ${ }^{40}$ The result indicated that the aluminosilicate film was gastight even though the film was as thin as $\sim 100 \mathrm{~nm}$. Therefore, this inorganic thin film is also promising as a corrosion-resistant coating.

In the present study, the aluminosilicate thin films, $\sim 60 \mathrm{~nm}$ thick and practically free from organic species, were fabricated by layerby-layer sol-gel processing on stainless steel substrates, and their corrosion protection properties were examined. Particular attention was paid to the influence of the total concentration of aluminum and silicon species in the precursor sol solution and it was found that the coatings obtained using a diluted precursor solution showed extremely high protection against pitting corrosion in $\mathrm{NaCl}$ solution.

\section{Experimental}

Amorphous aluminosilicate films were prepared from mixed precursor solutions of tetraethoxysilane (TEOS) (Kanto Chemical) and aluminum sec-butoxide $\left(\mathrm{Al}\left(\mathrm{O}^{\mathrm{s}} \mathrm{Bu}\right)_{3}\right)$ (Tokyo Chemical industry), as reported elsewhere. ${ }^{38}$ The substrate for the deposition, provided by JFE Steel Corporation, was Type 430 stainless steel sheets mirrorfinished by electrochemical-mechanical polishing. The films were deposited by multiple spin coating cycles in a layer-by-layer fashion. The precursor sol solutions were prepared as follows: $0.833 \mathrm{~g}$ of TEOS and $0.145 \mathrm{~mL}$ of $1 \mathrm{M}\left(\mathrm{mol} \mathrm{dm}^{-3}\right) \mathrm{HCl}$ were added to $10 \mathrm{~mL}$ of 1-propanol (1-PrOH). After stirring for $1 \mathrm{~h}$ at room temperature, 0.246 $\mathrm{g}$ of $\mathrm{Al}\left(\mathrm{O}^{\mathrm{s}} \mathrm{Bu}\right)_{3}$ was added to the stirred solution and the mixture was further stirred at $80^{\circ} \mathrm{C}$ for $40 \mathrm{~min}$ to obtain a precursor solution with the total $500 \mathrm{mM}$ concentration of aluminum and silicon species and the atomic ratio of $\mathrm{Al} / \mathrm{Si}=20 / 80$. The precursor solutions with the total concentrations of 50 and $100 \mathrm{mM}$ were prepared by the dilution of the $500 \mathrm{mM}$ solution with 1-PrOH. The precursor solutions containing aluminum species in addition to silicon species were selected because the more uniform coatings were readily obtained rather than silica coatings free from aluminum species.

The precursor sol solutions $(0.2 \mathrm{~mL})$ were spin-coated on to the stainless steel substrate at $3000 \mathrm{rpm}$ for $20 \mathrm{~s}$ by a Mikasa 1H-D7 spin coater. The coated specimen was exposed to hot air (Iuchi hot gun) for 120-240 s to promote further hydrolysis of the deposited gel layer, and then the substrate was cooled to room temperature by blowing cold air for $20 \mathrm{~s}$. Hydrolysis was checked by the wetting behavior of the surface during spraying water droplets. These cycles of spincoating, heating and cooling were repeated 10, 5, and 1 times for 

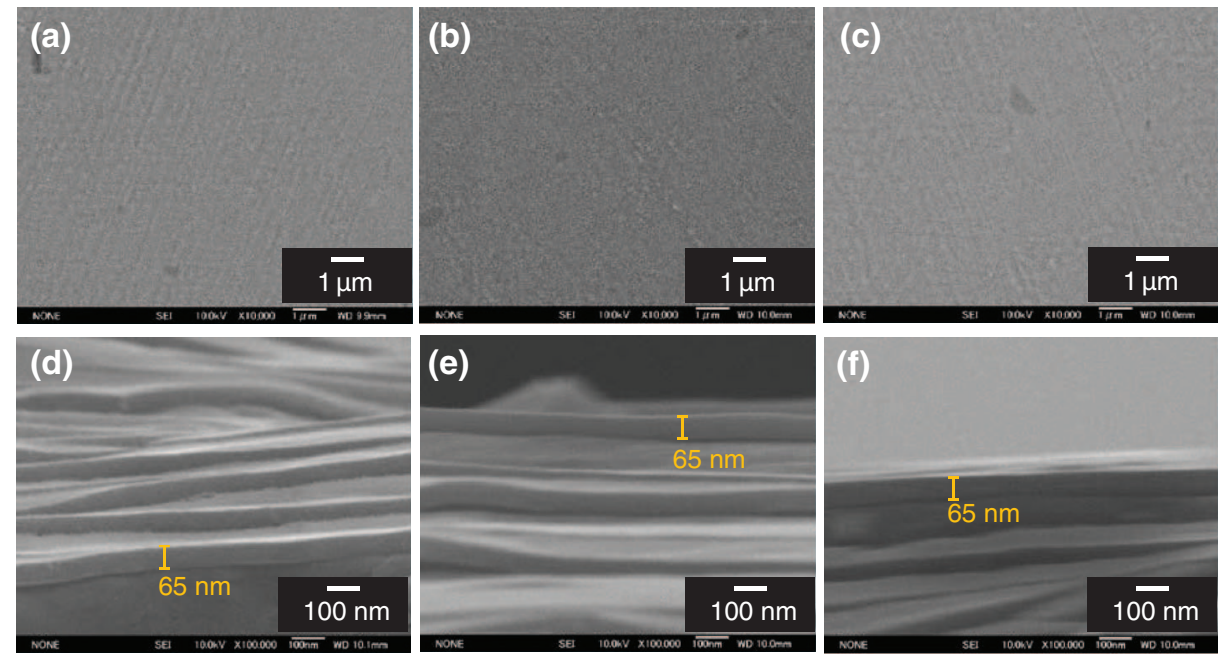

Figure 1. Scanning electron micrographs of (ac) the surfaces and (d-f) the fractured crosssections of the coated Type 430 stainless steel specimens obtained by multiple spin castings from $(\mathrm{a}, \mathrm{d}) 50 \mathrm{mM}$, (b,e) $100 \mathrm{mM}$, and $(\mathrm{c}, \mathrm{f})$ $500 \mathrm{mM}$ precursor solutions with spin casting cycles of 10,5 , and 1 , respectively, and subsequent annealing in air at $400^{\circ} \mathrm{C}$ for $1 \mathrm{~h}$. the 50,100 , and $500 \mathrm{mM}$ precursor sol solutions, respectively, to get $\sim 60$ nm-thick coatings. Finally, the obtained gel films were annealed in air at $400^{\circ} \mathrm{C}$ for $1 \mathrm{~h}$.

Surfaces and cross-sections of the coated specimens were observed by a JEOL JSM-6500F scanning electron microscope (SEM). The coated specimens were further characterized using a JASCO FT/IR350 FTIR spectrometer under a FTIR-RAS mode. The depth profile analysis was carried out using a Physical Electronics model PHI 660 scanning Auger microprobe. Depth profiles were also obtained using a Jobin-Yvon 5000RF GDOES instrument in an argon atmosphere of $800 \mathrm{~Pa}$ with application of RF of $13.56 \mathrm{MHz}$ and power of $40 \mathrm{~W}$. Light emissions of characteristic wavelengths were monitored throughout the analysis with a sampling time of $0.01 \mathrm{~s}$ to obtain depth profiles. The wavelengths of the spectral lines used were $121.567 \mathrm{~nm}$ (hydrogen), $130.217 \mathrm{~nm}$ (oxygen), $425.433 \mathrm{~nm}$ (chromium), $385.991 \mathrm{~nm}$ (iron), $288.158 \mathrm{~nm}$ (silicon) and $396.152 \mathrm{~nm}$ (aluminum). The signals were detected from a circular area of approximately $4 \mathrm{~mm}$ in diameter. $\mathrm{X}$-ray reflectometry measurements were carried out by a RIGAKU SmartLab system $(\mathrm{Cu} \mathrm{K} \alpha)$ equipped with a grazing incidence and reflectometry set-up. Data were analyzed using the GlobalFit software. Microhardness of the coated specimens was also evaluated by nanoindentation using an Elionix ENT-2100 with a Berkovich diamond indenter. The maximum load was $0.03 \mathrm{mN}$.

In order to determine the pitting potentials of the coated specimens, the specimens were potentiodynamically polarized to the anodic direction at a sweep rate of $0.33 \mathrm{mV} \mathrm{s}^{-1}$ in $3.5 \% \mathrm{NaCl}$ solution open to air at $298 \mathrm{~K}$. Platinum wire and $\mathrm{Ag} / \mathrm{AgCl}$ electrodes were used as the counter and the reference electrodes, respectively. At least four polarization measurements were carried out for each coated speci- men in order to confirm the reproducibility. The coated specimens $\left(50.2 \mathrm{~mm}^{2}\right)$ were exposed to the $\mathrm{NaCl}$ solution. Protective properties of the coated specimens were further examined by a cyclic salt spray test, consisting of a cycle of spraying of $5 \% \mathrm{NaCl}$ solution at $35^{\circ} \mathrm{C}$ for $2 \mathrm{~h}$, drying at $60^{\circ} \mathrm{C}$ for $4 \mathrm{~h}$, and wetting at $50^{\circ} \mathrm{C}$ and $>95 \%$ relative humidity for $2 \mathrm{~h}$. This cycle was repeated up to 30 times in this study.

\section{Results and Discussion}

Characterization of coatings. - Fig. 1 shows the surface and crosssection SEM images of the Type 430 stainless steel specimens coated from $50 \mathrm{mM}$ (Figs. 1a and 1d), $100 \mathrm{mM}$ (Figs. $1 \mathrm{~b}$ and $1 \mathrm{e}$ ), and $500 \mathrm{mM}$ (Figs. 1c and 1f) precursor solutions. Coatings with relatively smooth surfaces were obtained from all three precursor solutions (Figs. 1a1c), although small protrusions were developed during annealing at $400^{\circ} \mathrm{C}$. The protrusions may be associated with the thermal oxidation of the stainless steel substrate during annealing. The fractured crosssection SEM images (Figs. 1d-1f) depicted the uniform formation of $\sim 65 \mathrm{~nm}$-thick coatings from all three precursor solutions. Thus, the average thicknesses of the coatings per spin casting cycle are $6.5 \mathrm{~nm}$, $13 \mathrm{~nm}$, and $65 \mathrm{~nm}$ from the $50 \mathrm{mM}, 100 \mathrm{mM}$, and $500 \mathrm{mM}$ precursor solutions, respectively. Apparently, the thickness of the coating per spin casting cycle was in proportion to the metal concentration of the precursor solution

Fig. 2 shows the Auger electron spectroscopy (AES) depth profiles of the coated specimens. The depth profiles are similar for all three specimens and both silicon and aluminum species distribute uniformly in the coatings. The atomic ratio of silicon to aluminum is approximately 75:25, regardless of the concentrations in the precursor (a)

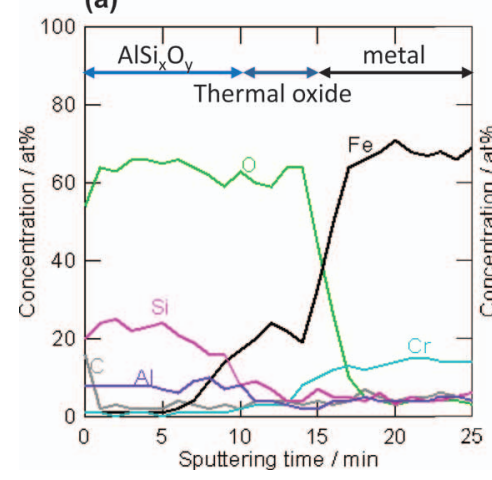

(b)

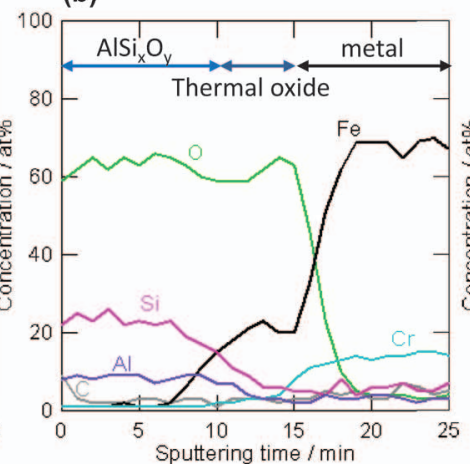

(c)

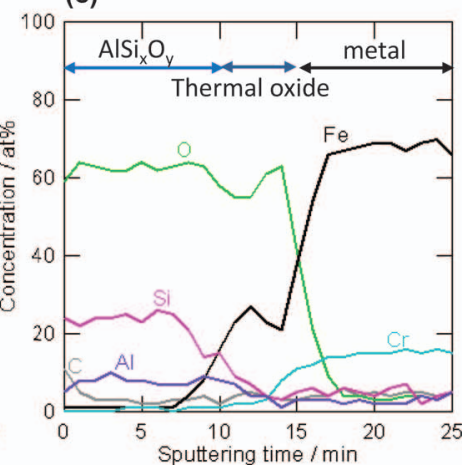

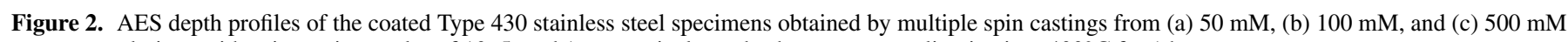
precursor solutions with spin casting cycles of 10,5 , and 1 , respectively, and subsequent annealing in air at $400^{\circ} \mathrm{C}$ for $1 \mathrm{~h}$. 
(a)

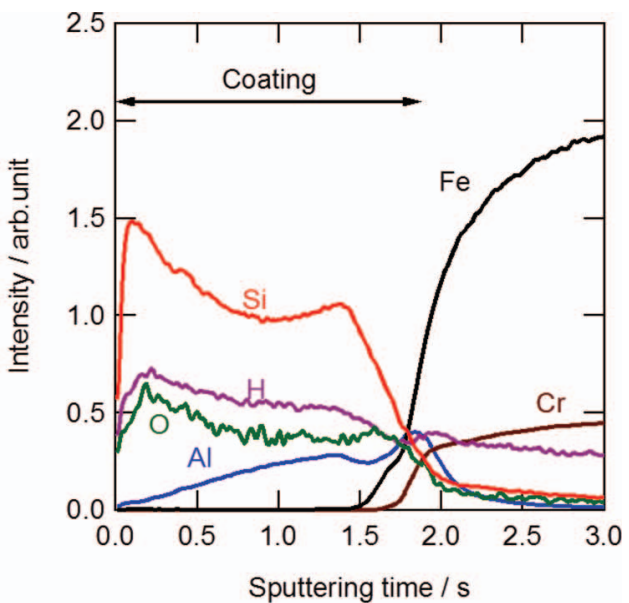

(b)

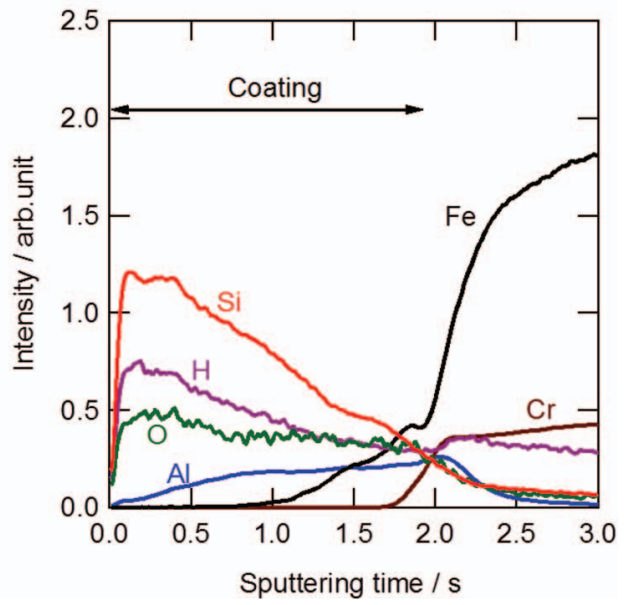

Figure 3. GDOES depth profiles of the coated Type 430 stainless steel specimens obtained from $50 \mathrm{mM}$ precursor solution with spin casting cycles of 10 (a) before and (b) after subsequent annealing in air at $400^{\circ} \mathrm{C}$ for $1 \mathrm{~h}$.

solution. The atomic ratio of aluminum to silicon in the coatings is higher than in the precursor solution, probably associated with the slower hydrolysis rate of TEOS compared with $\mathrm{Al}\left(\mathrm{O}^{s} \mathrm{Bu}\right)_{3}$. It is also obvious from Fig. 2 that iron species are incorporated in, approximately, the inner half of the coating thickness. Iron should be oxidized during annealing after multiple spin castings, diffusing into the aluminosilicate coatings. This was confirmed from the GDOES depth profile analysis (Fig. 3) of the specimens coated from the $50 \mathrm{mM}$ precursor solution with and without annealing in air at $400^{\circ} \mathrm{C}$. It is obvious from Fig. 3 that the incorporation of iron species into the coating occurs mainly during annealing. The intensities of aluminum and silicon in the coating are not constant in the GDOES depth profiles. This may be due to the presence of hydrogen. ${ }^{41}$ It is well known that the intensities of emission lines from a range of elements are influenced by the presence of even small quantities of hydrogen. The intensity of aluminum decreased due to an increase in the hydrogen content, while the opposite trend occurred for the intensity of silicon. ${ }^{41}$ In the outer part of the investigated coating, hydrogen species were incorporated, affecting the intensities of the aluminum and silicon profiles. Due to the opposite influence of hydrogen on their intensities, the intensity ratio of aluminum to silicon may not be constant throughout the coating in the GDOES depth profile.

Although SEM observations and AES depth profiles revealed the formation of similar coatings from the precursor solutions with different concentrations, X-ray reflectometry measurements disclosed a change in the coating density with the concentration of precursor solution. Fig. 4 shows small angle X-ray reflectometry scans of the coated specimens from three different precursor solutions. The reflectivity
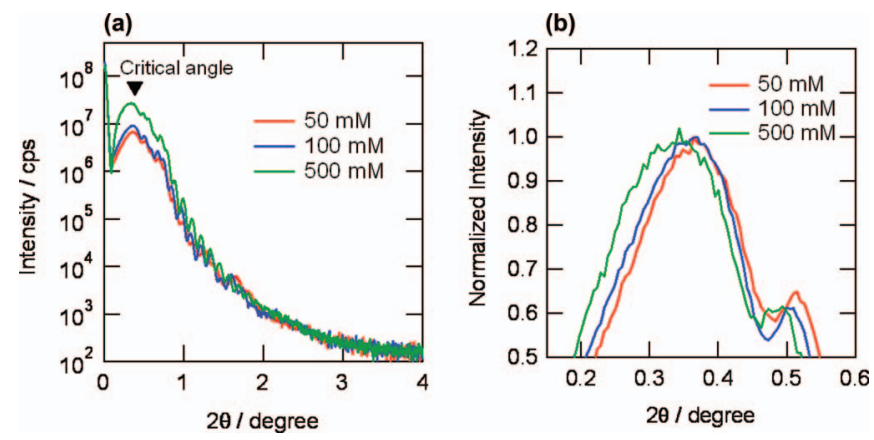

Figure 4. (a) X-ray reflectometry scans of the coated Type 430 stainless steel specimens obtained by multiple spin castings from (red) $50 \mathrm{mM}$, (blue) $100 \mathrm{mM}$, and (green) $500 \mathrm{mM}$ precursor solutions with spin casting cycles of 10,5 , and 1, respectively, and subsequent annealing in air at $400^{\circ} \mathrm{C}$ for $1 \mathrm{~h}$. (b) Enlargement of the peak region of (a) after normalization of the intensity.

intensity tends to decrease at $2 \theta=\sim 0.38^{\circ}$, which can be assumed to a critical angle. The critical angle shifts slightly toward a higher angle with a decrease in the concentration of precursor solution, which is obvious in Fig. 4b. The shift of the critical angle indicates the increased coating density is caused by reducing the concentration in precursor solution. The coating density estimated from the profile fitting is $\sim 2.2 \mathrm{~g} \mathrm{~cm}^{-3}$ for the coating from the $50 \mathrm{mM}$ precursor solution and $\sim 2.0 \mathrm{~g} \mathrm{~cm}^{-3}$ from the $500 \mathrm{mM}$ solution. The density of $2.2 \mathrm{~g} \mathrm{~cm}^{-3}$ is close to that of fused silica glass. At angles higher than the critical angle, the intensity oscillations are present. The width of the oscillations, reflecting the coating thickness, suggests that the thickness of the coatings is $\sim 70 \mathrm{~nm}$, almost in agreement with the SEM observations (Fig. 1).

Fig. 5 shows FTIR-RAS spectra of the three coated specimens. A strong Si-O vibration peak appears at $1000-1300 \mathrm{~cm}^{-1}$, associated mainly with an asymmetric stretching $\mathrm{Si}-\mathrm{O}$ vibration of a tetrahedral $\mathrm{SiO}_{4}$ coordination unit. ${ }^{42}$ The intensity of the $\mathrm{O}-\mathrm{H}$ stretching vibration observed as a broad peak in $3000-3600 \mathrm{~cm}^{-1}$ increases with an increase in the concentration of precursor solutions. The result of FTIR spectroscopy suggests that the coatings with fewer surface $\mathrm{OH}$ groups are developed from the precursor solutions with lower concentrations. The finding is consistent with the formation of more dense coatings by reducing the concentration in precursor solution. Because no $\mathrm{C}-\mathrm{H}$ vibration peaks were detected in FTIR spectra, organic species may not be incorporated in the coatings. The lower density of the coatings obtained from the solutions with higher precursor concentrations

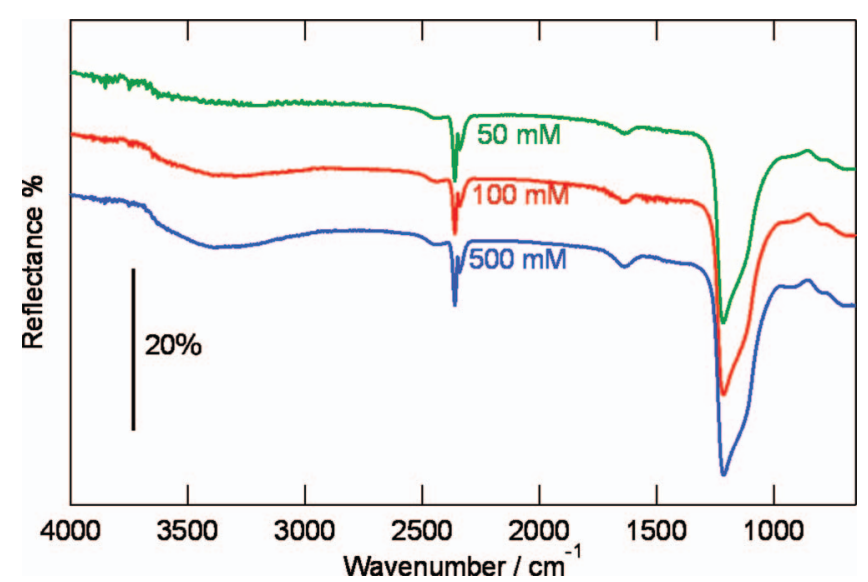

Figure 5. FTIR-RAS spectra of the coated Type 430 stainless steel specimens obtained by multiple spin castings from $50 \mathrm{mM}, 100 \mathrm{mM}$, and $500 \mathrm{mM}$ precursor solutions with spin casting cycles of 10,5 , and 1 , respectively, and subsequent annealing in air at $400^{\circ} \mathrm{C}$ for $1 \mathrm{~h}$. 


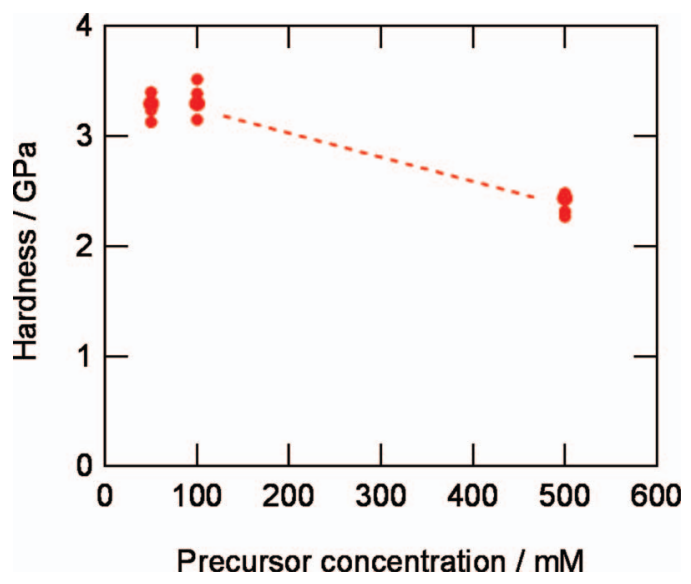

Figure 6. Nano-indentation hardness of the coated Type 430 stainless steel specimens obtained by multiple spin castings from $50 \mathrm{mM}, 100 \mathrm{mM}$, and $500 \mathrm{mM}$ precursor solutions with spin casting cycles of 10,5 and 1 , respectively, and subsequent annealing in air at $400^{\circ} \mathrm{C}$ for $1 \mathrm{~h}$, as a function of the concentration of precursor solution.

should be associated with higher porosity, as supported by increased peak intensities of surface $\mathrm{O}-\mathrm{H}$ stretching vibration. The surface $\mathrm{O}-\mathrm{H}$ groups should be present on the walls of micropores in addition to the outer coating surface and hence the intensity of the $\mathrm{O}-\mathrm{H}$ signal must be increased for the specimens coated from the precursor solutions with higher concentrations.

The change in the density of the coatings influenced the microhardness of the coatings. Fig. 6 shows the results of nano-indentation tests. For the measurements of mechanical properties of thin films by nano-indentation, it was reported that the indentation depth must be limited to less than $10 \%$ of the film thickness. ${ }^{43}$ In the present study, the indentation depth was 14-17 nm, which exceeded the $10 \%$ of the film thickness. Thus, the hardness values of coatings obtained from the load-depth curves may contain the influence of stainless steel substrate. However, because the same substrate was used in the present study and the coating thickness was similar, the change in the hardness of the coated specimens should be associated with the mechanical properties of the coatings themselves. It is obvious from Fig. 6 that the hardness of the coating obtained from $500 \mathrm{mM}$ precursor solution is lower than those obtained from the precursor solutions with lower concentrations, although no obvious difference in hardness between the coatings formed from the 50 and $100 \mathrm{mM}$ precursor solutions is seen. The reduced hardness of the coating obtained from the $500 \mathrm{mM}$ precursor solution may be related to the lower density and higher porosity of the coating.

Corrosion resistance of coated stainless steel. - The pitting potential of the coated Type 430 stainless steel was examined by potentiodynamic anodic polarization in $3.5 \% \mathrm{NaCl}$ solution (Fig. 7). The Type 430 stainless steel without coating shows the corrosion potential of $0.04 \mathrm{~V}$ vs $\mathrm{Ag} / \mathrm{AgCl}$. After showing a narrow passive potential region, the anodic current increases steeply at $0.11 \mathrm{~V}$ vs $\mathrm{Ag} / \mathrm{AgCl}$ due to pitting corrosion. Several pits could be seen on the specimen surface by the naked eye after polarization. The anodic polarization of the specimen coated with the $500 \mathrm{mM}$ precursor solution results in a steep current rise, due to pitting, from the corrosion potential of $0.0 \mathrm{~V}$ vs $\mathrm{Ag} / \mathrm{AgCl}$. The decrease in the pitting potential by this coating is associated with annealing at $400^{\circ} \mathrm{C}$ because the annealed Type 430 stainless steel without coating also showed pitting at $0.0 \mathrm{~V}$ vs Ag/AgCl. The decrease in pitting potential by annealing of the stainless steel may be associated with a micro-structural change of the stainless steel, such as the formation of chromium-depleted layer at the metal/film interface and/or the grain boundaries, although the detailed understanding of the influence of annealing on pitting potential of the stainless steel is not the subject of the present study.

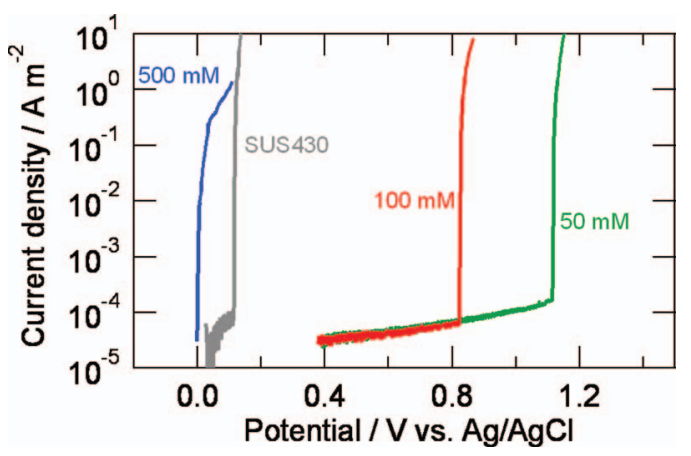

Figure 7. Potentiodynamic polarization curves measured in $3.5 \% \mathrm{NaCl}$ solution at room temperature for the Type 430 stainless steel specimens before and after coating by multiple spin castings from $50 \mathrm{mM}, 100 \mathrm{mM}$, and $500 \mathrm{mM}$ precursor solutions with spin casting cycles of 10, 5, and 1, respectively, and subsequent annealing in air at $400^{\circ} \mathrm{C}$ for $1 \mathrm{~h}$.

In contrast to the decrease in pitting potential by the coating from the $500 \mathrm{mM}$ precursor solution, marked increase in pitting potential occurs for the specimens coated from the 50 and $100 \mathrm{mM}$ precursor solutions. The pitting potential of the specimen coated from the $100 \mathrm{mM}$ precursor solution is $0.83 \mathrm{~V}$ vs $\mathrm{Ag} / \mathrm{AgCl}$ in Fig. 7, but the polarization curves of the five different specimens coated from the $100 \mathrm{mM}$ precursor solution revealed a variation of pitting potential between 0.07 and $0.99 \mathrm{~V}$ vs $\mathrm{Ag} / \mathrm{AgCl}$. Further higher pitting potential was obtained for the specimens coated from $50 \mathrm{mM}$ precursor solution, which revealed the pitting potential always higher than $1.0 \mathrm{~V}$ vs $\mathrm{Ag} / \mathrm{AgCl}$.

The corrosion resistance was further examined by a cyclic corrosion test. Fig. 8 shows the photos of the specimens after 30 cycles of (a)

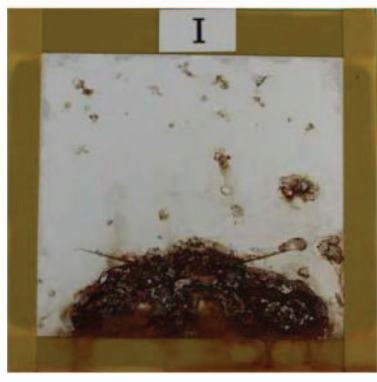

(c)

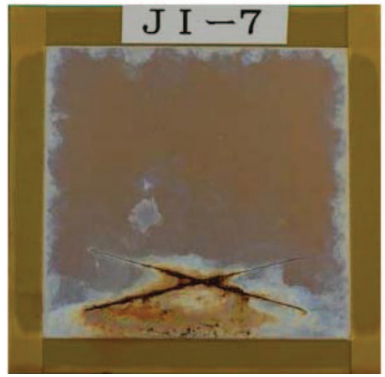

(b)

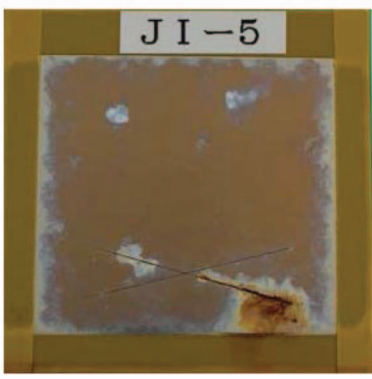

(d)

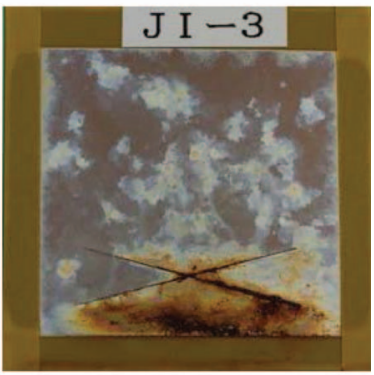

Figure 8. Surface appearance of the (a) non-coated and (b-d) coated Type 430 stainless steel specimens after 30 cycles of a cyclic corrosion test. The coated specimens were obtained by multiple spin casting from $50 \mathrm{mM}, 100$ $\mathrm{mM}$, and $500 \mathrm{mM}$ precursor solutions with spin casting cycles of 10, 5, and 1, respectively, and subsequent annealing in air at $400^{\circ} \mathrm{C}$ for $1 \mathrm{~h}$. In the images, the regions with lighter appearance are corroded and the darkest regions are covered with thick corrosion products. The regions of intermediate brightness (brown in color image) still show an interference color of the original coated specimens. 
a cyclic corrosion test. Prior to the corrosion test, the surface of the specimens (the bottom part of specimens in Fig. 8) was scratched to break a coating for accelerated corrosion. The corrosion was found across the entire surface of the specimen without coating (Fig. 8a). Thick corrosion products developed locally and at the bottom part of the specimen. In Figs. 8b-8d, brown color (intermediate brightness of the grayscale images) of the non-corroded regions is associated with the interference color of the coating. It is obvious from Fig. 8 that corrosion is suppressed by the coatings, particularly those obtained from the lower concentration precursor solutions. The number of corroded regions on the coatings obtained from 50 and $100 \mathrm{mM}$ precursor solutions is much lower than for the coatings from the $500 \mathrm{mM}$ solution. The corrosion of the scratched region becomes less significant by reducing the concentration of precursor solution. The penetration of the $\mathrm{NaCl}$ solution into the coating/substrate interface may be more effectively suppressed by the more dense coatings prepared from the lower concentration precursor solution.

\section{Conclusions}

In conclusion, the present study demonstrates that highly corrosion-protective coatings are obtained by sol-gel layer-by-layer deposition from diluted precursor solutions. The aluminosilicate amorphous thin coating, $\sim 65 \mathrm{~nm}$ thick, deposited on Type 430 stainless steel from $50 \mathrm{mM}$ precursor solution with $\mathrm{Al} / \mathrm{Si}=20 / 80$ shows the pitting potential higher than $1.0 \mathrm{~V}$ vs $\mathrm{Ag} / \mathrm{AgCl}$ in $3.5 \% \mathrm{NaCl}$ solution and improved corrosion resistance in the cyclic corrosion test. The coatings obtained from the diluted precursor solutions have higher density and lower porosity, improving the corrosion protection of the underlying steel. This study opens up a new approach for the fabrication of highly corrosion resistant coatings by a sol-gel process.

\section{Acknowledgments}

Thanks are due to Rigaku Corporation for the X-ray reflectometry measurements. A part of this work was conducted at Hokkaido University, supported by the "Nanotechnology Platform" Program of the Ministry of Education, Culture, Sports, Science and Technology (MEXT), Japan.

\section{References}

1. M. Guglielmi, J. Sol-Gel Sci. Technol., 8, 443 (1997).

2. D. C. L. Vasconcelos, J. A. N. Carvalho, M. Mantel, and W. L. Vasconcelos, J. Non-Cryst. Solids, 273, 135 (2000)

3. G. P. Thim, M. A. S. Oliveira, E. D. A. Oliveira, and F. C. L. Melo, J. Non-Cryst. Solids, 273, 124 (2000)

4. A. J. Lopez, E. Otero, and J. Rams, Surf. Coat. Technol., 205, 2375 (2010).
5. B. Nikrooz, M. Zandrahimi, and H. Ebrahimifar, J. Sol-Gel Sci. Technol., 63, 286 (2012).

6. V. H. V. Sarmento, M. G. Schiavetto, P. Hammer, A. V. Benedetti, C. S. Fugivara, P. H. Suegama, S. H. Pulcinelli, and C. V. Santilli, Surf. Coat. Technol., 204, 2689 (2010).

7. M. Atik and M. A. Aegerter, J. Non-Cryst. Solids, 147, 813 (1992).

8. M. Atik, C. R. Kha, P. Lima Neto, L. A. Avaca, M. A. Aegerter, and J. Zarzycki, J. Mater: Sci. Lett., 14, 178 (1995).

9. F. Perdomo, P. De Lima-Neto, M. A. Aegerter, and L. A. Avaca, J. Sol-Gel Sci. Technol., 15, 87 (1999).

10. J. W. Lee, C. W. Won, B. S. Chun, and H. Y. Sohn, J. Mater. Res., 8, 3151 (1993).

11. J. Masalski, J. Gluszek, J. Zabrzeski, K. Nitsch, and P. Gluszek, Thin Solid Films, 349, 186 (1999).

12. D. Wang and G. P. Bierwagen, Progress in Organic Coatings, 64, 327 (2009).

13. J. Dedamborenea, N. Pellegri, O. Desanctis, and A. Duran, J. Sol-Gel Sci. Technol., 4, 239 (1995).

14. W. J. van Ooij and T. Child, Chemtech, 28, 26 (1998).

15. T. F. Child and W. J. Van Ooij, Trans. Inst. Met. Finish., 77, 64 (1999).

16. H. Sayilkan, Ş. Şener, E. Şener, and M. Sülü, Mater. Sci., 39, 733 (2003).

17. S. Ono, H. Tsuge, Y. Nishi, and S.-i. Hirano, J. Sol-Gel Sci. Technol., 29, 147 (2004)

18. A. Conde, J. Damborenea, A. Durán, and M. Menning, J. Sol-Gel Sci. Technol., 37, 79 (2006).

19. J. M. Hu, L. Liu, J. Q. Zhang, and C. N. Cao, Progress in Organic Coatings, 58, 265 (2007).

20. M. F. Montemor and M. G. S. Ferreira, Progress in Organic Coatings, 63, 330 (2008).

21. Y. Tamar and D. Mandler, Electrochim. Acta, 53, 5118 (2008).

22. T. P. Chou, C. Chandrasekaran, S. Limmer, C. Nguyen, and G. Z. Cao, J. Mater. Sci. Lett., 21, 251 (2002).

23. T. P. Chou, C. Chandrasekaran, and G. Z. Cao, J. Sol-Gel Sci. Technol., 26, 321 (2003).

24. S. S. Pathak, A. S. Khanna, and T. J. M. Sinha, Corros. Rev., 24, 281 (2006).

25. M. L. Zheludkevich, R. Serra, M. F. Montemor, I. M. M. Salvado, and M. G. S. Ferreira, Surf. Coat. Technol., 200, 3084 (2006).

26. C. Jing and J. Hou, J. Appl. Polym. Sci., 105, 697 (2007).

27. S. V. Lamaka, M. F. Montemor, A. F. Galio, M. L. Zheludkevich, C. Trindade, L. F. Dick, and M. G. S. Ferreira, Electrochim. Acta, 53, 4773 (2008).

28. S. K. Poznyak, M. L. Zheludkevich, D. Raps, F. Gammel, K. A. Yasakau, and M. G. S. Ferreira, Progress in Organic Coatings, 62, 226 (2008).

29. A. L. K. Tan and A. M. Soutar, Thin Solid Films, 516, 5706 (2008)

30. S. Zheng and J. Li, J. Sol-Gel Sci. Technol., 54, 174 (2010).

31. R. Akid, M. Gobara, and H. Wang, Electrochim. Acta, 56, 2483 (2011).

32. K. J. Croes, A. J. Vreugdenhil, M. Yan, T. A. Singleton, S. Boraas, and V. J. Gelling, Electrochim. Acta, 56, 7796 (2011).

33. B. J. Basu, A. Srinivasan, J. Manasa, and V. K. W. Grips, Surface Engineering, 28 294 (2012)

34. K. K. Jena, T. K. Rout, R. Narayan, and K. V. S. N. Raju, Polym. Int., 61, 1101 (2012)

35. T.-H. Kuo, C.-J. Weng, C.-L. Chen, Y.-L. Chen, C.-H. Chang, and J.-M. Yeh, Polymer Composites, 33, 275 (2012).

36. Y. Aoki, T. Kunitake, and A. Nakao, Chem. Mater, 17, 450 (2005)

37. G. Freiman, P. Barboux, J. Perrière, and K. Giannakopoulos, Thin Solid Films, 517, 2670 (2009).

38. Y. Aoki, H. Habazaki, and T. Kunitake, J. Am. Chem. Soc., 131, 14399 (2009).

39. Y. Aoki, E. Muto, S. Onoue, N. Aiko, and T. Kunitake, Chem. Commun., 2396 (2007).

40. Y. Aoki, H. Habazaki, and T. Kunitake, Electrochem. Solid State Let., 11, P13 (2008).

41. V. D. Hodoroaba, V. Hoffmann, E. B. M. Steers, and K. Wetzig, J. Anal. At. Spectrom. 15, 1075 (2000).

42. M. Schraml-Marth, K. L. Walther, A. Wokaun, B. E. Handy, and A. Baiker, $J$. Non-Cryst. Solids, 143, 93 (1992)

43. S. J. Bull, J. Phys. D: Appl. Phys., 38, R393 (2005). 